Editorial

\title{
The International Year of Light in Spain
}

\section{El Año Internacional de la Luz en España}

Este cuarto número del $48^{\circ}$ volumen de OPA cierra el año 2015, año declarado por la ONU como Año Internacional de la Luz y de las tecnologías basadas en la luz. Es por ello que en este editorial deseamos hacer una breve revisión y valoración de este acontecimiento internacional en España.

La declaración de la ONU ha reconocido la importancia de ciencia y la tecnología de la luz para la vida de los ciudadanos y para el futuro desarrollo de la sociedad global a muy diversos niveles, y ha destacado la importancia que el aumento de la concienciación mundial y el fortalecimiento de la enseñanza en estos campos tiene para abordar retos de la sociedad. Asimismo, ha pretendido promover las vocaciones científicas entre los jóvenes y hacer visible el trabajo de las mujeres en el ámbito científico y tecnológico.

El Año Internacional de la Luz y de las tecnologías basadas en la luz es un proyecto educacional y de divulgación de amplia repercusión internacional, al que se han sumado las principales organizaciones ligadas al ámbito científico y tecnológico de la luz.

Con objeto de coordinar e impulsar las actividades relacionadas con este evento en España, en mayo de 2014 se constituyó el Comité Español del Año Internacional de la Luz. Este Comité ha intentado hacer visible a la sociedad española la gran importancia que las tecnologías basadas en la luz tienen ya hoy en día, y que constituyen unas tecnologías claves del desarrollo en los próximos años.

Es por ello que el Comité Español no solamente ha incluido a las sociedades e instituciones científicas relacionadas, tales como la Sociedad Española de Óptica - SEDOPTICA, la Real Sociedad Española de Física - RSEF, las universidades, el Consejo Superior de
Investigaciones Científicas (CSIC), el Sincrotrón ALBA de Barcelona, y la RACAB. También incorporó a centros científicos y tecnológicos, incluidos los dos centros de la red europea de láseres en España, ICFO y CLPU, y as plataformas industriales relacionadas con tecnologías basadas en la luz, SECPhO, AIDO y Fotónica21, así como instituciones y asociaciones del ámbito energético y de iluminación como el Comité Español de Iluminación - CEI, la asociación APDI, y el instituto de investigación IREC. Finalmente, el Comité ha contado también con el apoyo de la FECYT, la Fundación Española de Ciencia y Tecnología.

De esta manera, desde el Comité Español se ha pretendido que las actividades del Año Internacional de la Luz en España se beneficiaran de una importante colaboración y sinergia entre los diferentes agentes relacionados, incluyendo el ámbito académico, el sector tecnológico, y el entorno industrial.

Entre los hitos más importantes que se han obtenido cabe destacar que Su Majestad la Reina Doña Letizia aceptase presidir el Comité español de Honor del Año Internacional de la luz.

Inmediatamente después de su constitución, el Comité Español del Año Internacional de la Luz impulsó la creación del portal web español (www.luz2015.es), mantenido desde SEDOPTICA y sostenido en el servidor del CSIC. Este portal ha mantenido la visibilidad de las actividades y ha tenido una media de más de 3000 visitas mensuales.

El Comité Español se ha implicado de forma directa con una lista de casi 100 actividades y no son, ni mucho menos, el total de los actos que se han celebrado en España. Estas actividades se han realizado en universidades, centros de investigación, sociedades científicas, asociaciones culturales, museos, escuelas, institutos de 


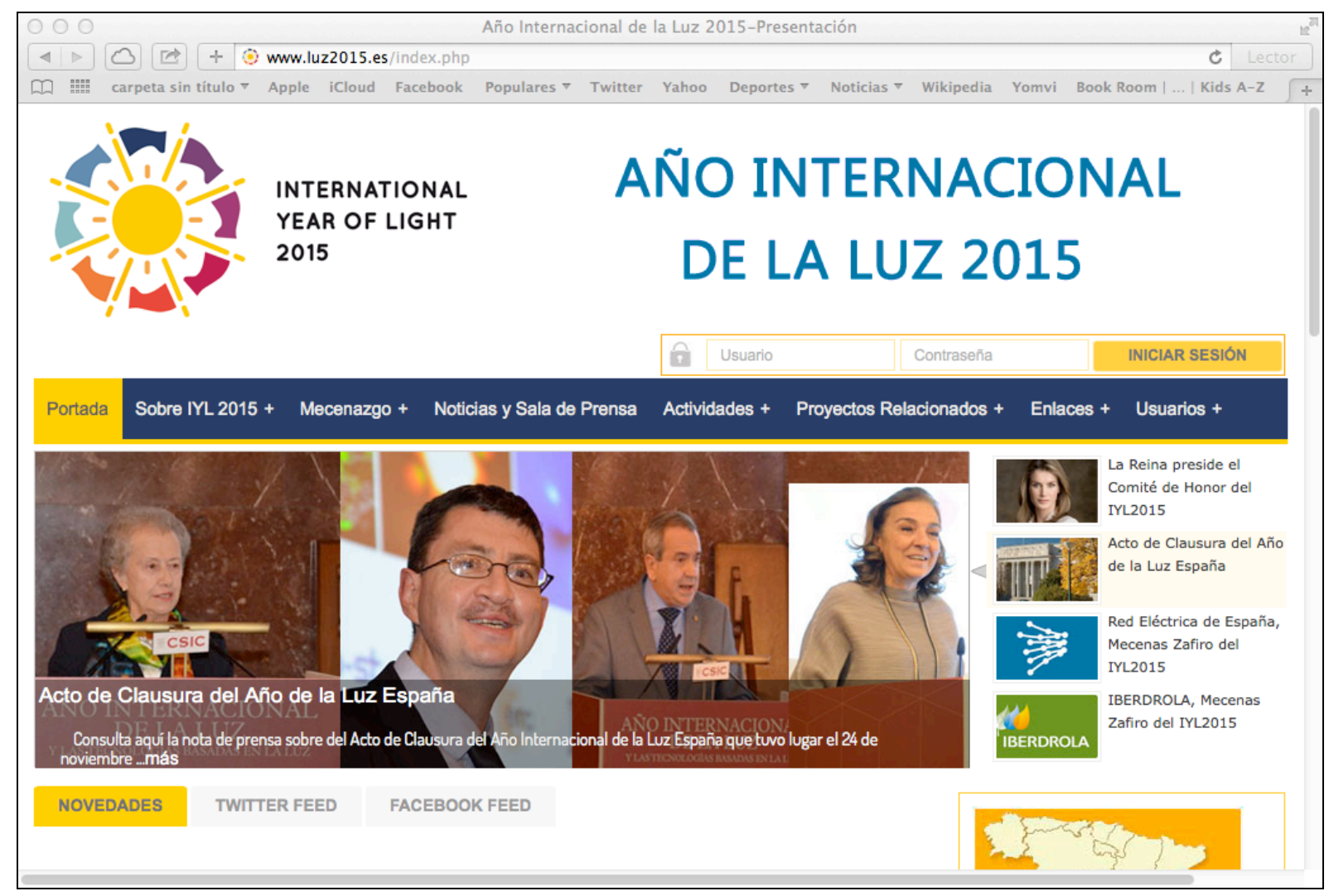

Fig. 1. Portal español del Año Internacional de la Luz: http://www.luz2015.es

enseñanza media, campamentos juveniles etc. En el portal se han recogido 90 conferencias, 23 jornadas científicas, 14 congresos, 51 proyectos docentes, 43 proyectos artísticos e industriales y 59 proyectos de divulgación. Es destacable también reseñar el amplio material divulgativo almacenado en el portal y que abarca 36 videos y 10 audios, 9 documentos de material grafico, 40 artículos divulgativos, 13 podcasts de radio, 43 noticias de prensa y televisión y 11 entrevistas. Especialmente valiosa ha sido la aoprtación en este aspecto de la UNED con la elaboración de numeroso material de video y audio. Se ha evaluado el alcance de las actividades que conocemos y se puede decir que hemos llevado a más de un millón de personas el mensaje del Año Internacional de la luz.

El Acto de Inauguración del Año Internacional de la Luz en España se realizó el 16 de febrero de 2015 en Barcelona, en el Teatro Poliorama de la Reial Academia de Ciencies i Arts de Barcelona, contando con la participación de tres conferenciantes invitados, el Dr. Ignacio Cirac, la
Dra. Caterina Biscari y el Dr. Geroni Nadal, y la actuación musical del maestro Lluis Claret.

Asimismo, el pasado día 24 de noviembre tuvo lugar el Acto de Clausura del Año Internacional de la Luz España en la Sede del CSIC. El acto contó con la participación de la Secretaria de Estado de Investigación, Desarrollo e Innovación, Dña. Carmen Vela, del presidente del CSIC Dr. Emilio Lora-Tamayo, y del Presidente del Comité Directivo Internacional del IYL2015, el Dr. John Dudley, que presentó una conferencia invitada.

El Comité Español del Año Internacional de la Luz ha mantenido la relación con el Comité Internacional. Una representación española acudió al acto de inauguración a nivel internacional, celebrado en Paris en la sede de la UNESCO. Asimismo, una representación española participará en el Acto Clausura a nivel internacional que tendrá lugar en la Ciudad de Mérida en Méjico en la primera semana de febrero de 2016.

Todo esto se ha conseguido gracias al apoyo de muchos. Desde SEDOPTICA, además del 
mantenimiento del portal web, hemos colaborado en la realización de actividades relacionadas en los eventos de la Sociedad realizados este año, especialmente en la IX Reunión Nacional de Optoelectrónica - Optoel'15, y en la XI Reunión Nacional de Óptica - RNO, celebradas ambas en Salamanca en Julio y en Septiembre de 2015 respectivamente. También la revista OPA abrió este año una sección específica para presentación de trabajos de divulgación conmemorando el Año Internacional de la Luz, con una excelente acogida.

Deseamos agradecer la activa colaboración especialmente de la RSEF, así como del CSIC, las universidades y los centros de investigación. También a las entidades y empresas que han colaborado económicamente como mecenas y cuyos nombres constan en el portal www.luz2015.es, así como a las empresas colaboradoras de SEDOPTICA. La figura 2 muestra las entidades que han participado en el Comité Español del Año Intrenacional de la Luz, así como las empresas patrocinadoras.

Para terminar, deseamos trasmitir que, una vez que hemos alcanzado a la sociedad con un destacable éxito a lo largo de este año, no queremos detenernos aquí y queremos animar a todos a continuar con este proyecto educacional y divulgativo en el futuro. Nosotros haremos el esfuerzo de plasmar en un informe las actividades realizadas y procuraremos guardar el material didáctico y divulgativo existente en el portal. Esperamos su apoyo.

Barcelona, Diciembre de 2015

María J. Yzuel

Presidenta del Comité Español del Año Internacional de la Luz

Santiago Vallmitjana

Presidente de SEDOPTICA

Ignacio Moreno

Vicepresidente de SEDOPTICA

DOI: http://dx.doi.org/10.7149/OPA.48.4.i

\section{Agradecimientos}

SEDOPTICA agradece a FECYT la financiación recibida para las actividades del Año Internacional de la Luz a través del proyecto " Proyectando el Año Internacional de la Luz", Ref.: FCT-14-8598

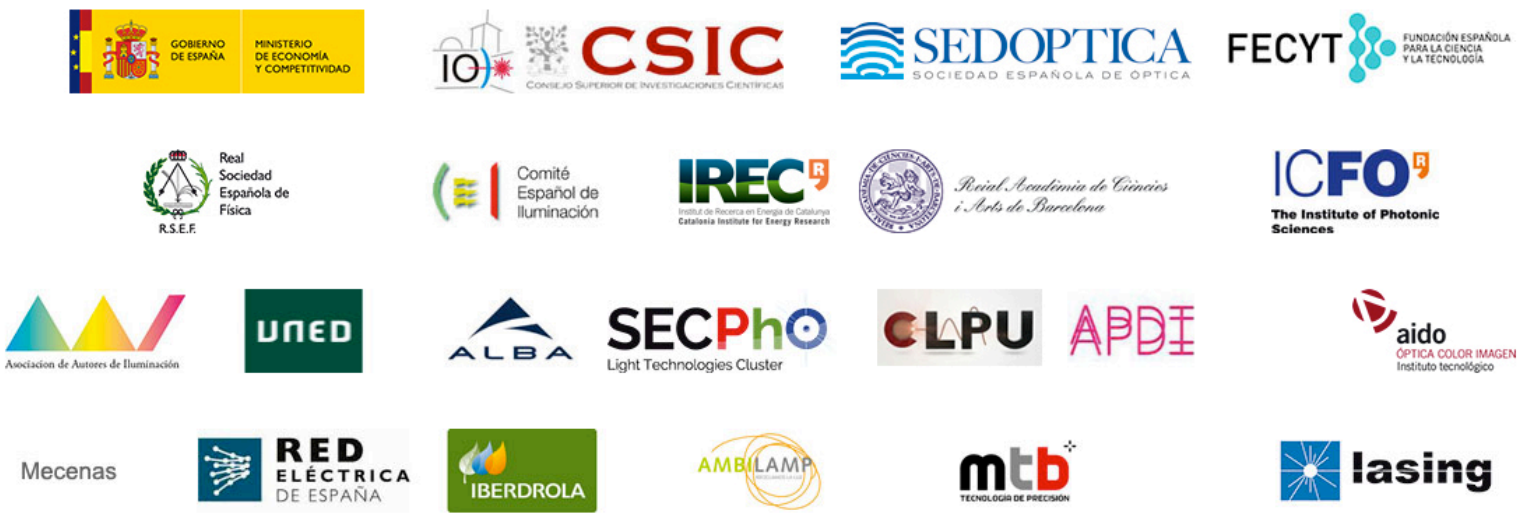

Fig. 2. Entidades patrocinadoras del Año Internacional de la Luz en España: http://www.luz2015.es 